\title{
Joan Miro. 1960s: In Search of a New Artistic Language, Close Contacts With the Cultures of the USA and Japan
}

\author{
Ksenia Orlova ${ }^{1, *}$
}

\author{
${ }^{1}$ Department of Contemporary Art of the West, State Institute of Art (SIAS), Moscow, Russia \\ *Corresponding author.E-mail: ksenia.orlova.1976@mail.ru
}

\begin{abstract}
For the already famous Catalan artist Joan Miro, the 1960s have been marked by success in the East and his most active work in America. Japan and the United States had a tremendous impact on Miro's creativity and a world-view. On the one hand, Miro has always been a man who looked for solitude and peace, harmony of body and spirit, possibility of full concentration on creativity - this can explain his attraction to the Eastern cultures. On the other hand, he wanted to go beyond his creative potential and to destroy his own ideas about art; despite the fact that he had already passed many stages, including the "killing of painting", he continued moving forward - Miro was still looking for contemporary artistic language, new opportunities for self-expression - and America promised the master his next phase, a new cycle of development.
\end{abstract}

Keywords: Miro, artistic language, surrealism, sculpture, ceramics, mosaics, asceticism, self-portrait,

triptych, abstraction

\section{INTRODUCTION}

The 1960s were not a formative phase for the Catalan artist Joan Miro: he was already a worldfamous master of surrealism and abstract art by then, his exhibitions were held with overwhelming success in Europe and the United States. That period was not a crucial turning point in his work either - the artist had been developing in the tideway of his own idea of art, finding new techniques, trying on the new directions and using all of his old achievements. Nevertheless, we cannot say that the '60s do not have striking features in the Miro's work. He masters the art of ceramics, becomes involved with tapestries, lithography. Finally, he gets his first Studio in Palma de Mallorca, which allows Miro to turn to the paintings and sculpture of a larger size. Miro's expansion to the East and his most active work in America are precisely about '60s.

That way, during the one of his trips to New York, Miro was acquainted with the art of young American artists such as Arshile Gorky and Jackson Pollock. He was also very impressed by the abstract expressionism of Robert Motherwell and Mark Rothko. "This painting showed me the degree of freedom one can reach when follow the path without recognizing any boundaries. To a degree, it liberated me from conventions", Miro said in an interview with Yvon Taillandier [1].

At the very end of the 1950s and 1960s, his works appear to be striking with their simplicity, even asceticism: the nature of the line changes, it gradually becomes harder, rigid, and the volume of black color increases. Already in the 1953 work "Painting" the line takes a dominant place - it magically creates an amazing transparent anthropomorphic character on a malachite background, a bird, a star and an incomprehensible creature similar to a seahorse. The picture is very ironic. Irony often comes from the light dotty strokes around the rough black lines. They serve to soften the sharpness of repulsive characters. Perhaps Miro's fascination with the East prompted him to experiment with black color (black lines and black spots). He created several horizontal and vertical calligraphy scrolls, quite impressive in length, and began actively engaging in ceramics and lithography. All that led the master to a greater introspection in painting.

\section{JAPAN}

In the 50s, while in the United States, Miro devoted himself to the art of the Far East, as it was very popular there ${ }^{1}$.

It was then that Miro got a desire to visit Japan. However, the trip took place only in 1966 on occasion of a major retrospective exhibition in Tokyo and Kyoto. Miro had an honor of personally meeting there the poet and art critic Shuzo Takiguchi ${ }^{2}$. Takiguchi was into

First trip in 1947, then in 1950,1950 s-1960s retrospective exhibitions and frequent visits

2 Shuzo Takiguchi (1903-1979) 
surrealism and devoted a number of works to this movement; he translated into Japanese the work "Surrealism in Painting" by Andre Breton. He knew many surrealists and took a special interest in Miro's painting. Takiguchi believed that Miro's searches in painting were going in the same direction as his searches in poetry. Both of them wanted to go beyond the usual visual language, calligraphy and words. Thus, in 1940, he was the first to write a work on the art of the Catalan master ${ }^{3}$. For a long time it was the only monograph about Miro in the world, and the artist was very proud of it. Until 1966, the poet tried several times to be acquainted with Miro. However, the personal relationship and correspondence between Miro and Takiguchi started only when the poet found out about the upcoming retrospective exhibition of the artist in Tokyo. Takiguchi wrote a self-presentation letter to Miro, in which he reminded of the written by him monograph, announced his participation in the work on a new catalog of this retrospective and invited Miro to visit him.

They had several amazing collaborations, demonstrating the incredible convergence of Japanese poetry and Catalan painting, where Miro showed a keen understanding of the traditions of the Japanese calligraphy and the possibility of its interpretation. Takiguchi admired the artist's calligraphy, his ability to play with words and drawings on the surface of paper.

In 1966, Miro received a very warm welcome in Japan. He managed to visit museums, where he so closely encountered the ancient art of this country for the first time. He was struck by sculpture and ceramics. Miro saw the collections of soft-core prints in private ownership - from the most ancient to modern; he was surprised with frank naturalness and sexuality of these works, their certain irony and, at the same time, the delicacy and elegance of their performance. Many of Miro's works are also noted for a subtle eroticism, it always runs through the artist's paintings, creating a special mood on his canvases. Miro said in an interview, "I was fascinated by the work of Japanese calligraphers and, of course, it influenced my technique. Now I work more and more falling into trance, almost always being in a state of trance. And each time I gain more significance in my painting" [2].

For Miro, Japan became a symbol of the unity of poetry and painting, a symbol of harmony, achieved balance and equilibrium in art. This trip gave him a new impetus to create sculptures and ceramics, calligraphy and prints.

The fascination with the East in the 1960s is even more noticeable in the asceticism of his works. He follows the same path but it become more aggravated and even exaggerated on many levels. Miro puts all the

Shūzō Takiguchi "Miró" primitive power into his artistic language, gives a dominant role to the black line; he outlines the wild aggressive forms with a single gesture; the light irony, which was evident earlier, disappears in these works. Examples are "Woman and bird" (1963) and "Figure and bird" (1963). On some canvases, such as "Figure and the bird in the sun" (1963), a white forming line appears in addition to the black line, which immediately softens a perception of the painting, the characters no longer look so aggressive and repulsive.

\section{SELF-PORTRAIT}

The history with the Re-newed Self-portrait is illustrative for this period. Artist painted the waist up, front view Self-portrait I 1937-38. This is a pencil drawing on canvas with a slight oil impregnation, $146 \times 97 \mathrm{~cm}$, with meticulously painted fine details. Miro proportionally increases his own image by 3 times in relation to the real size and interprets the image the same way he previously wrote his detailed landscapes but adds new images of his inner world: stars, sun, floral lines, flames, various symbols, which intertwine showing the face of the master. In the arabesque of the painting, Miro turns the lines of his jacket into the sparks of a huge fire. There is a solar sign (heart) on his chest, an imitation of the heavenly hosts in his eyes and another sparkling star - a tie knot. His chin and lips have become a source of a real energy, a kind of incandescent lamp; suns have been spinning and some celestial bodies are being born on his cheeks; his hair is a flying fire... Swirling stars and a turning into a flame ladder appear around the figure... Self-portrait is a perception not only of the own physical being, appearance and face but of the own spiritual content of the creature. The solution on internal conflicts and worldview challenges of the artist is depicted as a specific moment of self-contemplation, self-knowledge; and as an outcome - on the canvas - we have a reflection of the endless process of personal development.

Miro, after repeatedly working out details and endlessly correcting his drawing with an eraser, was afraid that he would lose it and ordered a copy of the latest drawing to Freisz, the assistant of architect Paul Nelson ${ }^{4}$. Freisz made an exact copy of the drawing on canvas, preserving its dimensions. Then this drawing was sold and sent to America, and Miro had only a copy; he was able to get back to work on it only in 1960. Directly on the copy of Freisz, he draws a thick black line. This line follows the outline of the image, including some symbols and signs that define the portrait of the artist: 3 hairs, a red circle containing the eye-sun, a reminiscence of the landscape symbolized by the shoulders, a yellow spot in honor of the shirt he wanted to wear to paint the self-portrait many years

4 There are two spellings of his surname - Freisz and Freiss. 
ago. The new Self-portrait is a strong and ironic obliteration of the old one made by using a bold black graphical line, accented with a few spots and a dazzling red circle framing the eye. However, this destruction of the portrait and even a certain confession of the artist, coming from 1937, does not erase the elements that remain under the fresh graphics. It seems that the artist himself wanted to hide but not disappear behind the new character, so it was easier to exist.

Revising the concept of the Self-portrait taken in 1937, Miro claims, without realizing it, the final breakup with all the previous stages of his work.

His self-portrait reveals itself as a kind of treatise on art, as a picturesque concept of himself as a Founder, Creator and an Artist, with a capital A. That is why so much time has been devoted to that portrait in the report.

Back to the fascination with the East, asceticism and the domination of the black line, to be fair, we note that other works appear with no black shaping lines, the line is rather present in the form of a stroke or a small detail. Now the artist is playing with the background sometimes the canvas is completely black and then it remains completely white, often the background is an untouched surface of the cardboard or paper. Signs, symbols, spots, lines, splashes and smudges suddenly appear on the whitewashed spaces of the canvas; they form the subtle images in which you can hardly guess a star, a woman, a bird. Examples are the paintings "Joy of a girl in the sun" (1960) and "Red disk" (1960).

On the Miro's canvases, mysterious outlines of figures appear through the sophisticated patterns of spots, which are all mixed and leading an observer into confusion. Only a trajectory remains from the bird, the stars with more simplified forms are not as bright as before but still recognizable: "Solitude I" (1960), "Painting IV-V" (1960).

\section{TRIPTYCHES}

Since the mid-1960s, Miro became interested in painting the series of triptychs. While maintaining the asceticism of his artistic language, he tried to create the most emotional works. Perhaps, that was resulted by impression from the paintings of American abstract expressionist. Using minimal means of expressing, Miro wants to shock the observer, to plunge him into deep reflection and emotional stress. To achieve the effect of detachment, artist uses canvases of a huge size. This is why empty spaces become absolutely crucial [3]. Some of the most famous series of this period are the fairly large-format triptych "Blue I", "Blue II", "Blue III" and the "Painting for the temple". Concise nature of paintings refers to the works of 1925 and to the symbolism of that time. Universe, microcosm, time, space - they are all in this triptych. It is surprisingly musical and poetic. In this triptych, artist returns to his favorite subject of fusion between poetry and painting.

One of Miro's goals in these works is to express the theme of emptiness inside and outside the painting canvas, being extremely concise. This is an extremely relevant topic for the art of the 1960s. Mark Rothko is a perfect example (once Michelangelo Antonioni, looking at his work, said, "Your paintings are like my movies... They are very accurate... and they are about nothing" [4]). Both conceptualists, for example, Yves Klein's "Leap into the void" (1960) and minimalists, for example, Donald Judd's "Untitled" (1967) tried to interpret it in their own way. Overall, the main unifying for all was an idea of emptiness as the opposition of one world to another - the world of reality to the world of fantasy and dreams, themselves to the alienated society, our own solitude to the loneliness of the modern world in general. This topic was raised not only in the fine arts but also in the theater, poetry and cinema (for example, some works of the early 1960s by M. Antonioni that emphasize the metaphysical nature of emptiness). Miro thinks through the composition, color and material of his works at that period. There are no spontaneity and random findings in them. Huge preparatory work precedes the creation of triptychs: dozens of sketches, drawings and recordings that Miro compared to a religious ritual, and their execution - to a battle that took all his strength. Two years later, Miro painted a green, red and orange triptych inspired by "Blue": "Painting for the temple I", "Painting for the temple II" and "Painting for the temple III". Miro uses here a successfully found solution. The artist creates like the variants of "Blue" by changing the color, directing the line somewhat differently: the line plays a main role here. The artist re-creates a sense of cosmic space, motif of a star road, passing comet and interrupted trajectory of a shooting star...

Later, Miro returned with pleasure to this poetic realm of dreams and fantasy, to unearthly visions, to beauty and purity, to his magical world: "The Lark's Wing, encircled with golden blue, rejoins the heart of the poppy sleeping in a diamond-studded meadow" (1967), "The gold of the azure" (1967), "Hair pursued by two planets" (1968) and, of course, "Woman encircled by a flight of birds in the night" (1968).

In 1968, Miro again created a triptych "Painting on a white background for the cell of recluse". Here, the asceticism of his expressive means, perhaps, reaches its apogee: the artist completely rejects the color and focuses on line and gesture. Thanks to the confident gesture, rigid clear black line appears on the huge white canvases $(270 \times 355 \mathrm{~cm}, 267 \times 350 \mathrm{~cm}, 267.5 \times 351.5 \mathrm{~cm})$. White canvases symbolize the space of a reclusory, while the line represents a poor hermit locked within four walls. This recluse, according to Dupin's subtle 
remark, can only scratch on the wall a cardiogram of his pain and hope with the fingernail. On the first canvas, the line passes with a slight incline from almost the left corner to almost the right corner (deviating slightly down). On the second one, it quickly rushes from the top down and rounds at the end, not allowing, itself to escape beyond the canvas. On the third canvas, the line climbs from the bottom up, as if from the foot of a mountain to its top. Peace of mind - despair hope... An amazing simplicity, even asceticism that conveys the pain, loneliness, despair and yet the hope of a lonely man.

"These canvases are the culmination of everything I had tried to do", Miro later said of the triptychs [5].

\section{V. "MAY 1968"}

I would like to highlight another canvas "May 1968" painted by the master in 1973. This is a somewhat belated but still a reaction to the student unrest that swept through Paris in May $1968^{5}$. Painting has two layers. The first layer is colored, viable and full of positive energy: red spots, lines and tangles, green circles, little spots, orange shapes, thaw holes of pure white canvas, yellow egg-sun... And the dark clumps of paint, rough black lines, splashes, smudges, painted circles, the artist's palms are thrown on top of it ... Cheerful Paris and student protests that led to demonstrations, riots and a nearly 10-million-strong general strike. The artist's favorite city, filled with slogans, painted over with graffiti, blocked with barricades. Miro very accurately recaptured the atmosphere of those difficult and crucial for France days.

The presence of a large amount of black along with a few pure colors, in principle, has become a characteristic feature of some of the Miro's later works. These dark elements were raging on the canvases in the early 1960 s. However, in the late $60 \mathrm{~s}$, this is no longer a thick outline, spots or shadows on the colorful background but rather the opposite. Rare bright flashes of color among the dark masses and rough lines: "Catalan peasant in the moonlight" (1968), "Woman and birds" (1968). However, there are exceptions: for example, in the 1966 painting "The skiing lesson", a combination of a gray background and a pattern applied to it, similar to stained glass, where black strokes frame the bright color spots, creates a completely different impression.

The May 1968 events, or "Red May", or May 1968, were a social crisis in France that began with left-wing radical student unrest and escalated into demonstrations, riots and a nearly 10-millionstrong general strike. It eventually led to a change of government, the resignation of President Charles de Gaulle, and, more broadly, to the huge changes in French society.

\section{CONCLUSION}

As repeatedly stated, Miro used his painting discoveries throughout his creative life. Miro, having once studied a certain style and direction, having mastered the skills, has never forgotten it. Those discoveries became an integral part of his artistic language. Then, when the artist needed to achieve a certain effect in painting, the technique, which was necessary for that particular work, was coming to his mind. The 1960s are very indicative in this sense.

Miro, as a true artist, responds to all the trends of this time and even anticipates some of them. Let us recall the story of the Self-portrait: the artist pieced together his universe in 1937-1938, and in the 60s, with the help of a bold black graphical line, accented with spots and a red circle, he makes an ironic and almost conceptual gesture. I must say that this transformation scared a lot the Miro's critics and art dealers. In general, there was an interesting situation in the art market during those years. People have come to an understanding of the art market as a complex, detailed system that operated according to its own strict internal laws. Naturally, that led to a kind of artistic and intellectual reaction on the part of artists, in particular on the part of Miro. The system was getting more commercialized and more, and artists, including the Catalan master, set their goal in principle to create the art that would be inconvenient to sell. The echo of that opposition materialized in Conceptualism and in the rise of Happenings, literally in everything at that time. In the early $70 \mathrm{~s}$, it led Miro to the burnt canvases and much more.

Miro's new asceticism was just a continuation of the search for his artistic language that would harmonize with the era of the $60 \mathrm{~s}$. The depth, infinite selfknowledge, and self-irony, appropriate to the creators of that time, gave the Miro's abstract art a touch of minimalism and even conceptualism. The search for precise, clear, concise statements, reflecting a spirit of that time, led him to deconstruction of the image, which was so popular in those years. Many features of the 1960s art were clearly and distinctively displayed in the artist's works. The new asceticism of Miro is a result of the self-irony of the artists in sixties, of their commitment to deconstruction, their delight in the philosophical emptiness of the canvas, minimalism and conceptuality of the available for them means of expression.

\section{References}

[1] G. Raillard, "Conversations with Miró", Barcelona, 1998, p. 369-370

[2] J. Miró, "Writings and conversations by Margit Rowell", Valencia-Murcia, 2002. p. 368. 
[3] Y. Mink, "Joan Miro. 1893-1983", Moscow: Art-Rodnik, 2003. p. 87.

[4] I. Miller, "Michelangelo Antonioni: peering into the void". URL: https://www.peremeny.ru/column/view/912/ (access date: 09.07.2020).

[5] R. Bernier, "Propos de Joan Miró, Lausana, "L'Oeil", 1961, Julio-Agosto, no. 79-80, pp. 7-9. Cit. ex: Joan Miró, "Graphic work". La Polígrafa, S.A., Barcelona, España, 1978, p.435. 